\title{
Low positive predictive value of midnight salivary cortisol measurement to detect hypercortisolism in type 2 diabetes
}

Charlotte Steffensen ${ }^{1}$, Henrik H. Thomsen ${ }^{1,2}$, Olaf M. Dekkers ${ }^{3,4,5}$, Jens S. Christiansen ${ }^{1}$, Jørgen Rungby ${ }^{6}$, Jens Otto L. Jørgensen ${ }^{1}$

${ }^{1}$ Department of Endocrinology and Internal Medicine, Aarhus University Hospital, ${ }^{2}$ Department of Medicine, Viborg Regional Hospital ${ }^{3}$ Department of Medicine, Section Endocrinology, Leiden University Medical Center, Leiden, The Netherlands, ${ }^{4}$ Department of Clinical Epidemiology, Aarhus University Hospital

${ }^{5}$ Department of Clinical Epidemiology, Leiden University Medical Center, Leiden, The Netherlands, ${ }^{6}$ Centre for Diabetes Research, Gentofte University Hospital, DK - 2900 Hellerup, Denmark

\section{OBJECTIVES}

- Hypercortisolism is prevalent in type 2 diabetes (T2D), but analytical and functional uncertainties prevail

- The usefulness of salivary cortisol in the context of T2D is uncertain

- The objective of this study was to determine sensitivity, specificity and accuracy of a single LNSC with the $1 \mathrm{mg}$ DST as reference standard in T2D patients.

\section{METHODS}

- 382 patients ( 150 women and 232 men, median age 62 (range 23 - 85) years) recruited from the Danish Centre for Strategic Research in Type 2 Diabetes (DD2) Project (12), and diagnosed with T2D after January 2009, participated in the study.

- Exclusion criteria were: use of any kind of exogenous glucocorticoids or estrogen containing medications, psychiatric disease, alcohol intake $>14$ units/week for men and 7 units/week for women, and evidence of any acute medical condition

- Cut - off values for hypercortisolism: LNSC $\leq 3.6 \mathrm{nmol} / \mathrm{l}$ and DST $\leq 50 \mathrm{nmol} / \mathrm{l}$.

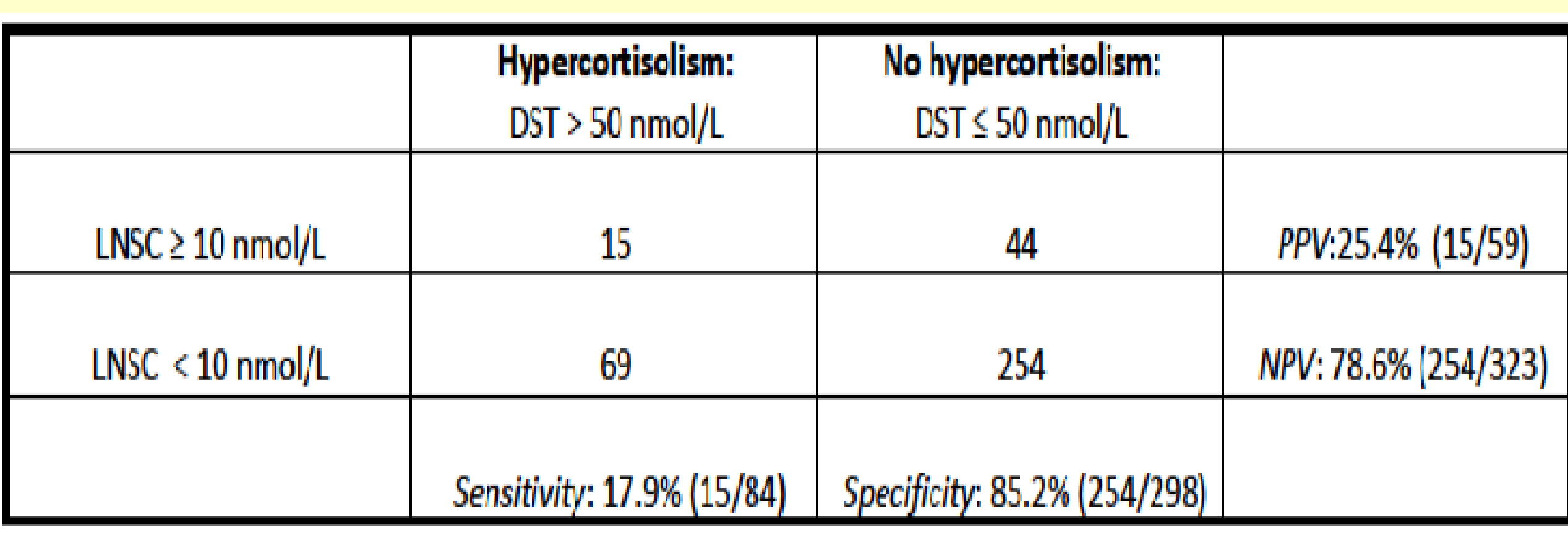

\begin{tabular}{|c|c|c|c|}
\hline & $\begin{array}{l}\text { Hypercortisolism: } \\
\text { DST >50 nmol/LL }\end{array}$ & $\begin{array}{c}\text { No hypercortisolism: } \\
\text { DST } \leq 50 \mathrm{nmmol} / \mathrm{L}\end{array}$ & \\
\hline$\angle N S C \geq 3.6 \mathrm{nmol} / \mathrm{L}$ & 71 & 256 & PPV: $21.7 \%(71 / 327)$ \\
\hline LNSC $<3.6 \mathrm{rmol} / \mathrm{L}$ & 13 & 42 & $N P V: 76.4 \%(42 / 55)$ \\
\hline & Sensitivity: $84.5 \%(71 / 84$ & Specificity: 14.1\% (42/2928) & \\
\hline
\end{tabular}

Number of patients with hypercortisolism (DST $>50 \mathrm{nmol} / \mathrm{L}$ ) and measurements of $L N S C$ with cut - off value $\geq 3.6 \mathrm{nmol} / \mathrm{L}$ and $\geq 10$ nmol/L PPV, Positive Predictive Value; NPV, Negative Predictive Value

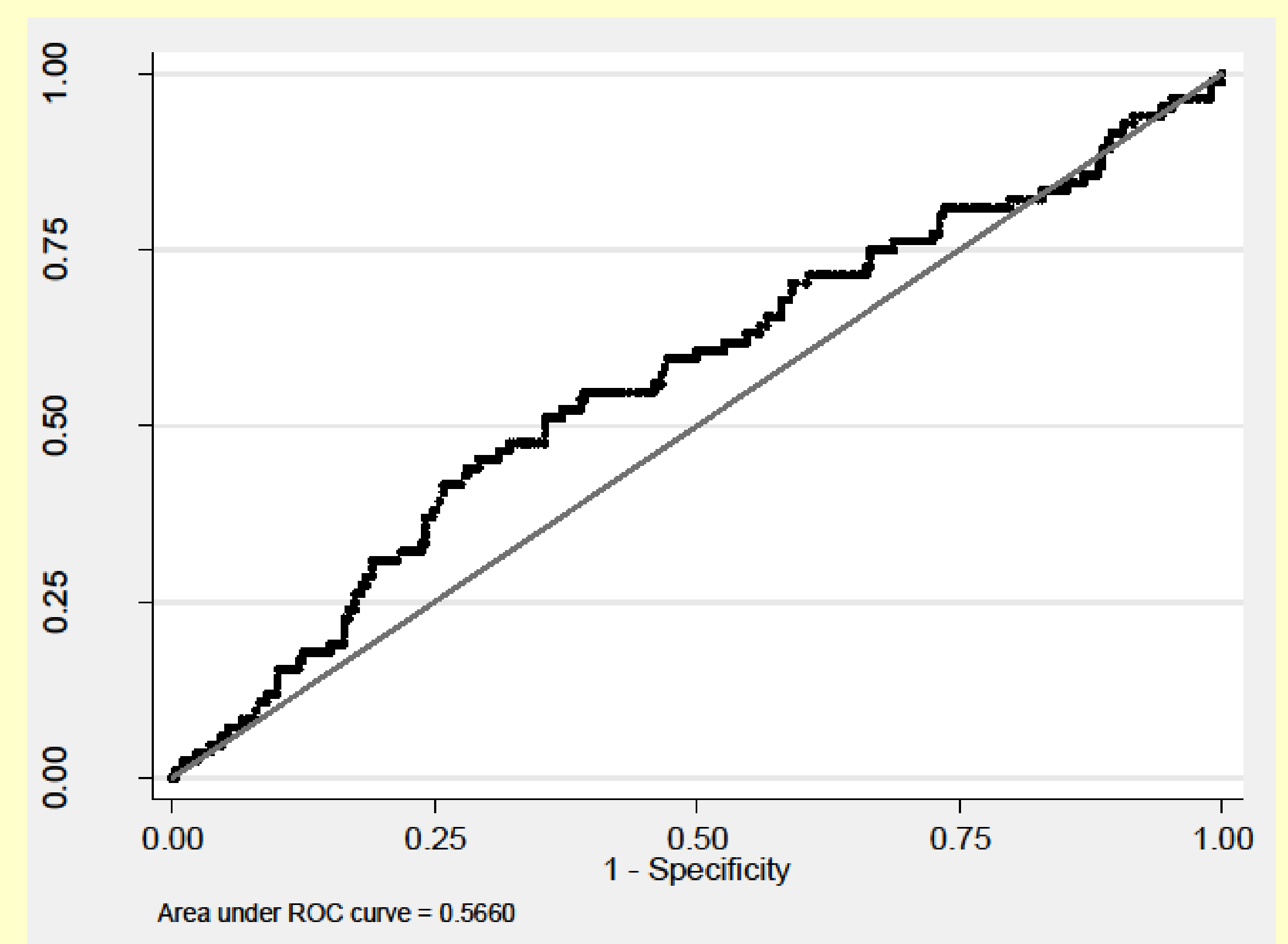

The area under the ROC curve (AUC) describes accuracy of LNSC compared to DST. An AUC value of 0.57 indicates very low discriminative value

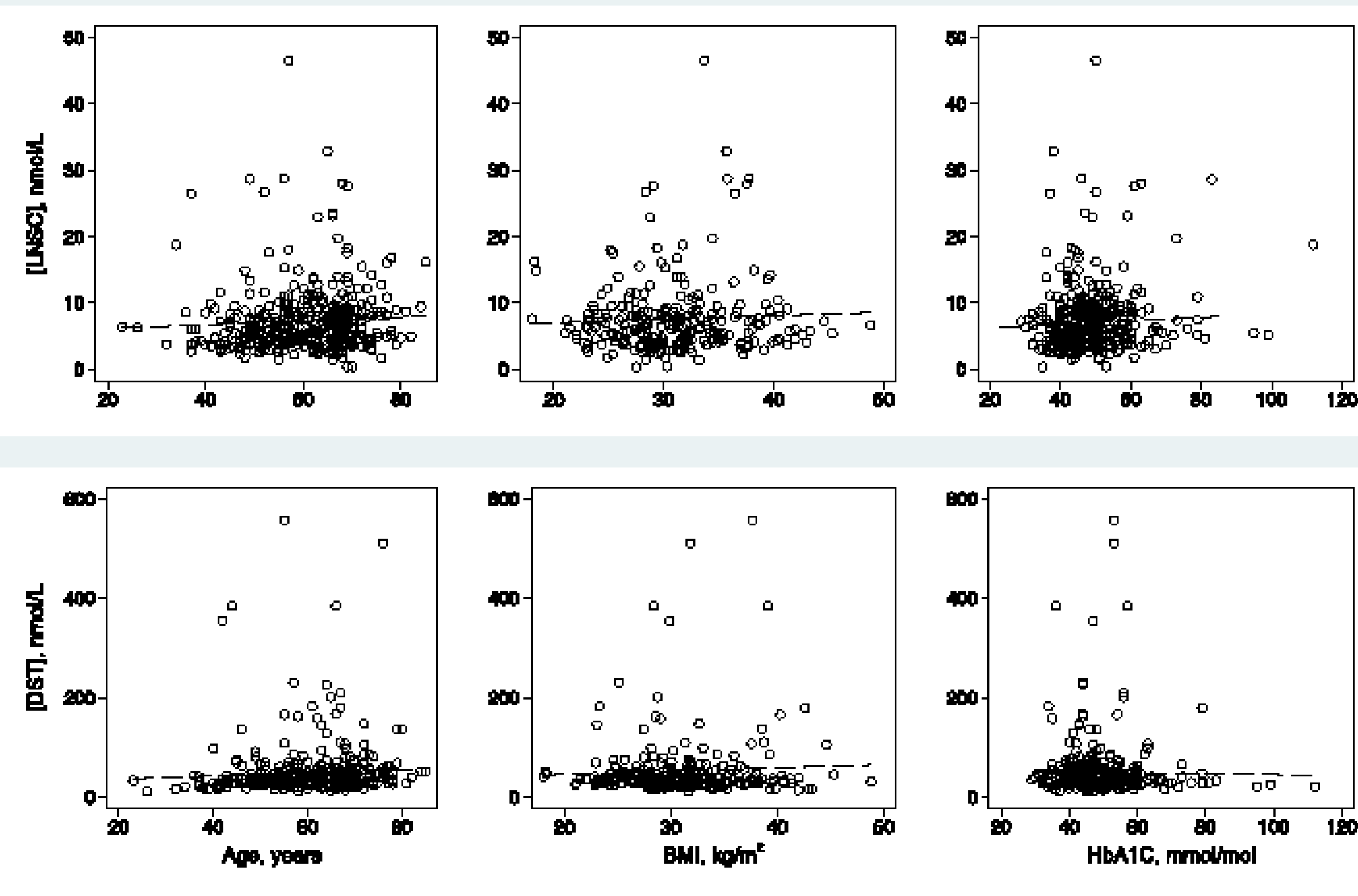

Association between age, $\mathrm{BMI}$, and $\mathrm{HbA} 1 \mathrm{C}$ and cortiso concentration in T2D patients. LNSC, late - night salivary cortisol DST, Dexamethasone suppression test; BMI, body mass index. LNSC and DST are in units of $\mathrm{nmol} / \mathrm{L}$, age in years, BMI in $\mathrm{kg} / \mathrm{m}^{2}$.

\section{RESULTS}

- 84 T2D patients (22\%) did not suppress serum cortisol $<50 \mathrm{nmol} / \mathrm{L}$ after $1 \mathrm{mg}$ DST

- 329 T2D patients (86\%) had elevated LNSC

- The sensitivity of LNSC was $85 \%$ and the specificity was $14 \%$

- Positive predictive value of LNSC was $22 \%$ and the negative predictive value was $76 \%$

- ROC curve: the area under the curve revealed an accuracy of LNSC of 0.57 (95\% Cl: $0.49-0.64)$

- Linear regression established that neither age, BMI, nor HbA1c could predict LNSC or DST

\section{CONCLUSIONS}

LNSC is characterized by very low specificity and poor positive predictive value to detect hypercortisolism in T2D

LNSC is not suitable as a stand-alone test to screen for hypercortisolism in T2D

Further methodological and clinical studies are needed to substantiate the relevance of cortisol status in $\mathrm{T} 2 \mathrm{D}$
References

Chiodini I, Torlontano M, Scillitani A, Arosio M, Bacci S, Di Lembo S, et al. Association of subclinical

hypercortisolism with type 2 diabetes mellitus: a case-control study in

hospitalized patients. Eur J Endocrinol [Internet]. 2005 Dec [cited 2014 Sep 23];153(6):837-44.

Raff H, Raff JL, Findling JW. Late-Night Salivary Cortisol as a Screening Test for Cushing 's Syndrome*. J Clin Endocrinol Metab. 1998;83(8):2681-6. 